Marquette University

e-Publications@Marquette

7-1-1974

Effect of Sodium Ions on the Electrochemical Reduction of Diethyl Fumarate in Dimethylsulfoxide and Acetonitrile

Michael D. Ryan

Marquette University, michael.ryan@marquette.edu

Dennis H. Evans

University of Wisconsin - Madison

Accepted version. Journal of the Electrochemical Society, Vol. 121, No. 7 (July 1974): 882-883. DOI. (C) 1974 Electrochemical Society. Used with permission.

Michael D. Ryan was affiliated with University of Wisconsin-Madison at the time of publication. 


\title{
Effect of Sodium Ions on the Electrochemical Reduction of Diethyl Fumarate in Dimethylsulfoxide and Acetonitrile
}

\author{
Michael D. Ryan \\ Department of Chemistry, University of Wisconsin-Madison \\ Madison, WI \\ Dennis H. Evans \\ Department of Chemistry, University of Wisconsin-Madison \\ Madison, WI
}

Childs et al. (1) studied the electrochemical reductive coupling of diethyl fumarate (trans- $\mathrm{C}_{2} \mathrm{H}_{5} \mathrm{O}_{2} \mathrm{CCH}=\mathrm{CHCO}_{2} \mathrm{C}_{2} \mathrm{H}_{5}$ ), 1 , in $\mathrm{N}, \mathrm{N}$ dimethylformamide (DMF). Their attention was focused on the dimerization mechanism with tetra-n-butylammonium iodide as supporting electrolyte. Using double potential step chronoamperometry, these workers showed that the initially formed radical anions reacted by a second-order, irreversible, dimerization reaction in contrast to more complex schemes which had been proposed earlier. This conclusion was confirmed for 1 and other activated olefins by later studies using rotating ring-disk electrode voltammetry (2), linear sweep voltammetry (3), and current-reversal chronopotentiometry (4).

Keywords: electrohydrodimerization, cyclic voltammetry, ion pairs.

Journal of the Electrochemical Society, Vol. 121, No. 7 (July 1974): pg. 882-883. DOI. This article is (C) Electrochemical Society and permission has been granted for this version to appear in e-Publications@Marquette. Electrochemical Society does not grant permission for this article to be further copied/distributed or hosted elsewhere without the express permission from Electrochemical Society. 
Childs et al. (1) noted that the addition of sodium or lithium ions to the supporting electrolyte caused a substantial increase in the rate of dimerization of the radical anions of diethyl fumarate. Lithium also had the effect of decreasing the importance of polymerization side reactions as evidenced by an increase of the coulometric n-value to unity. An analogous effect of sodium and lithium has been reported for the reduction of some $\alpha, \beta$-unsaturated ketones in dimethylsulfoxide (5). The increased rate of dimerization was ascribed to ion pair formation between the radical anions and the metal cations with the neutral ion pairs reacting more rapidly than the anion radicals. A quantitative study of the effect of sodium on the reduction of phthalaldehyde in $\mathrm{N}, \mathrm{N}$-dimethylformamide has been reported by Lasia (6) who treated his data in terms of the following reactions ( $A=$ phthalaldehyde)

$$
\begin{gathered}
\mathrm{A}+e \stackrel{E_{1 / 2}}{\rightleftharpoons} \mathrm{A}- \\
\mathrm{A}-+\mathrm{Na}^{+} \stackrel{K}{\rightleftharpoons} \mathrm{NaA} \cdot \\
2 \mathrm{~A}-\stackrel{k_{1}}{\longrightarrow}-\mathrm{AA}- \\
\mathrm{A}-\mathrm{NaA} \cdot \stackrel{k_{2}}{\longrightarrow}-\mathrm{AANa} \\
2 \mathrm{NaA} \cdot \stackrel{k_{3}}{\longrightarrow} \mathrm{NaAANa}
\end{gathered}
$$

If the rate of the ion pairing reaction [2] is rapid enough so that the reaction can be assumed to be at equilibrium, and if sodium is

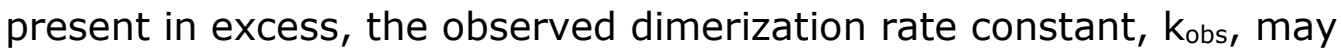
be related to $K, k_{1}, \mathrm{k}_{2}, \mathrm{k}_{3}$, and $C_{N a}$ by the equation

\section{$k_{o b s}=\left(k_{1}+k_{2} K C_{\mathrm{Na}}+k_{3} K^{2} C_{\mathrm{Na}}^{2}\right) /\left(1+K C_{\mathrm{Na}}\right)^{2} \quad[6]$ \\ where $K$ is the formation constant for the ion pair $\left(\mathrm{M}^{-1}\right)$ and $C_{N a}$ is the molar concentration of sodium.}


This paper presents results for the reduction of 1 in the presence of sodium in dimethylsulfoxide (DMSO) and acetonitrile (AN). Though these solvents have similar dielectric constants, the tendency for ion pair formation is much greater in AN than in DMSO. Fujinaga et al. (7) noted that formation constants for the ion pairs of the radical anions of naphthoquinones and metal ions are greater in AN than in DMSO. As pointed out by Krygowski (8), this is consistent with the concept of donicity ( $D N$ ) defined by Gutmann (9). A high donicity solvent such as DMSO ( $D N=29.8)$ stabilizes the unpaired metal ions by solvation in contrast to a lower donicity solvent such as AN ( $D N=$ 14.1 ) in which solvation of metal ions is weak and ion pair formation is favored.

\section{Experimental}

\section{Materials}

Dimethylsulfoxide (DMSO) and acetonitrile (AN) were Matheson Coleman and Bell Spectroquality solvents. Water content as determined by gas chromatography was about $30 \mathrm{mM}$ for each solvent. Tetra-n-butylammonium perchlorate (Matheson Coleman and Bell) was recrystallized from acetone-water and vacuum dried at room temperature. Anhydrous sodium perchlorate (Matheson Coleman and Bell) was found to contain less than 1 mole per cent $(\mathrm{m} / \mathrm{o})$ water by determining loss of weight after vacuum drying at $200^{\circ} \mathrm{C}(10)$. Diethyl fumarate (Aldrich) was used as received.

\section{Apparatus}

The voltammetric cell has been described elsewhere (11) as has the digital data acquisition system and procedures for analysis of cyclic voltammetric data (12). A silver reference electrode (SRE) comprising a silver wire in contact with $0.10 \mathrm{M}$ tetra-n-butylammonium perchlorate and $0.010 \mathrm{M}$ silver nitrate in DMSO was used for the DMSO studies and an aqueous saturated calomel electrode (SCE) was used in AN. The hanging mercury drop electrode area was $0.029 \mathrm{~cm}^{2}$.

\section{Experimental procedures}

Experiments were performed at a temperature of $24^{\circ} \pm 1^{\circ} \mathrm{C}$. For sodium perchlorate concentrations less than $0.10 \mathrm{M}$, sufficient tetra-n- 
butylammonium perchlorate was added to assure an ionic strength of $0.1 \mathrm{M}$

Rate constants were determined using the method described by Olmstead, Hamilton, and Nicholson (13) where the anodic peak current, $i_{a}^{\prime}$, is measured from zero current rather than from an extension of the cathodic peak. The theoretical results were extended to switching potentials necessary for this research but not encompassed in the work of Olmstead et al. by applying digital simulation techniques (14). The rate law for dimerization of the radicals, $R$, was written as $-\mathrm{dC}_{\mathrm{R}} / \mathrm{dt}=2 \mathrm{kC}_{\mathrm{R}}^{2}$ where $k$ is the secondorder dimerization rate constant. Olmstead et ca. omitted the 2 in their formulation of the rate law.

\section{Results and Discussion}

Peak potentials and observed rate constants, $\mathrm{k}_{\mathrm{obs}}$, as a function of sodium concentration for DMSO as solvent are presented in Table I. The rate constants are averages of individual values obtained from at least three different scan rates in the range of $0.5-50 \mathrm{~V} / \mathrm{sec}$. The shapes of the voltammetric peaks, the peak current ratios, and the dependence of the cathodic peak potential on scan rate were all consistent with an irreversible dimerization following reversible electron transfer (13).

There are several constants which must be evaluated in Eq. [6]. The dimerization rate constant for the radical anions, $\mathrm{k}_{1}$, was taken as $\mathrm{k}_{\mathrm{obs}}$ in the absence of sodium ions. The value found was $1.4 \times 10^{3}$ liter mole $^{-1} \mathrm{sec}^{-1}$. The evaluation of $K$ is based on the dependence of the peak potential on sodium concentration. Two factors cause the peak potential to move in the positive direction as the sodium concentration increases. First, the ion pair formation (reaction [2]) causes a positive shift in the potential. This would be observed even if the radicals did not dimerize. Second, the chemical reactions of the anion radicals, reactions [3] - [5], also cause a positive shift in the peak potential. Since the two effects are additive, we may correct the observed peak potentials for the effects of the second factor by applying the theory for an irreversible dimerization 
NOT THE PUBLISHED VERSION; this is the author's final, peer-reviewed manuscript. The published version may be accessed by following the link in the citation at the bottom of the page.

reaction following a reversible electron transfer reaction (13) to the observed peak potentials and rate constants in Table I. ${ }^{1}$

Table I. Dependence of peak potential and $k_{\text {obs }}$ on sodium concentration for the reduction of diethyl fumarate in $\mathrm{DMSO}^{\mathrm{a}}$

\begin{tabular}{|c|c|c|}
\hline$C_{\mathrm{Na}}, M$ & $E_{D}^{b}$ & $\begin{array}{c}k_{\text {obs }} \times 10-s \\
\text { liter } \cdot \text { mole }^{-1} \text { sec }^{-1}\end{array}$ \\
\hline $\begin{array}{l}0.0 \\
0.004 \\
0.0063 \\
0.010 \\
0.016 \\
0.025 \\
0.040 \\
0.064 \\
0.10 \\
0.16 \\
0.25 \\
0.40 \\
0.63\end{array}$ & $\begin{array}{l}-1.728 \\
-1.724 \\
-1.724 \\
-1.717 \\
-1.711 \\
-1.705 \\
-1.699 \\
-1.692 \\
-1.692 \\
-1.684 \\
-1.674 \\
-1.659 \\
-1.645\end{array}$ & $\begin{array}{c}1.4 \\
3.4 \\
4.7 \\
6.6 \\
11 \\
17 \\
24 \\
35 \\
38 \\
60 \\
97 \\
170 \\
445\end{array}$ \\
\hline
\end{tabular}

a $0.96 \mathrm{mM}$ diethyl fumarate; $24^{\circ} \mathrm{C}$; tetra-n-butylammonium per-chlorate added to solutions containing low sodium concentrations to bring total ionic strength to about $0.1 \mathrm{M}$.

b V vs. SRE; $0.050 \mathrm{~V} / \mathrm{sec}$.

\footnotetext{
${ }^{1}$ This procedure is based on the fact that the boundary value problem comprising reactions [1]151 is of the same form as that solved by Olmstead et al. (13) when it is assumed that reaction [2] is fast and that the diffusion coefficients of the radical anion and ion pair are identical. The formulation treats the sum of the radical anion and ion pair concentrations as a new variable. The rate constant in the formulation is kobs from Eq. [6] and the standard potential includes the effect of reaction [2], i.e., it is given by $E^{\circ}+0.0592 \log \left(1+\mathrm{KC} \mathrm{Na}_{\mathrm{a}}\right)$. Hence, the theoretical data of Ref. (13) may be used to evaluate $k_{\text {obs. }}$. Furthermore, the shifts in peak potential as the sodium concentration is changed are due to both the kinetic effect and the shift in the formal potential. The two effects are additive.
} 


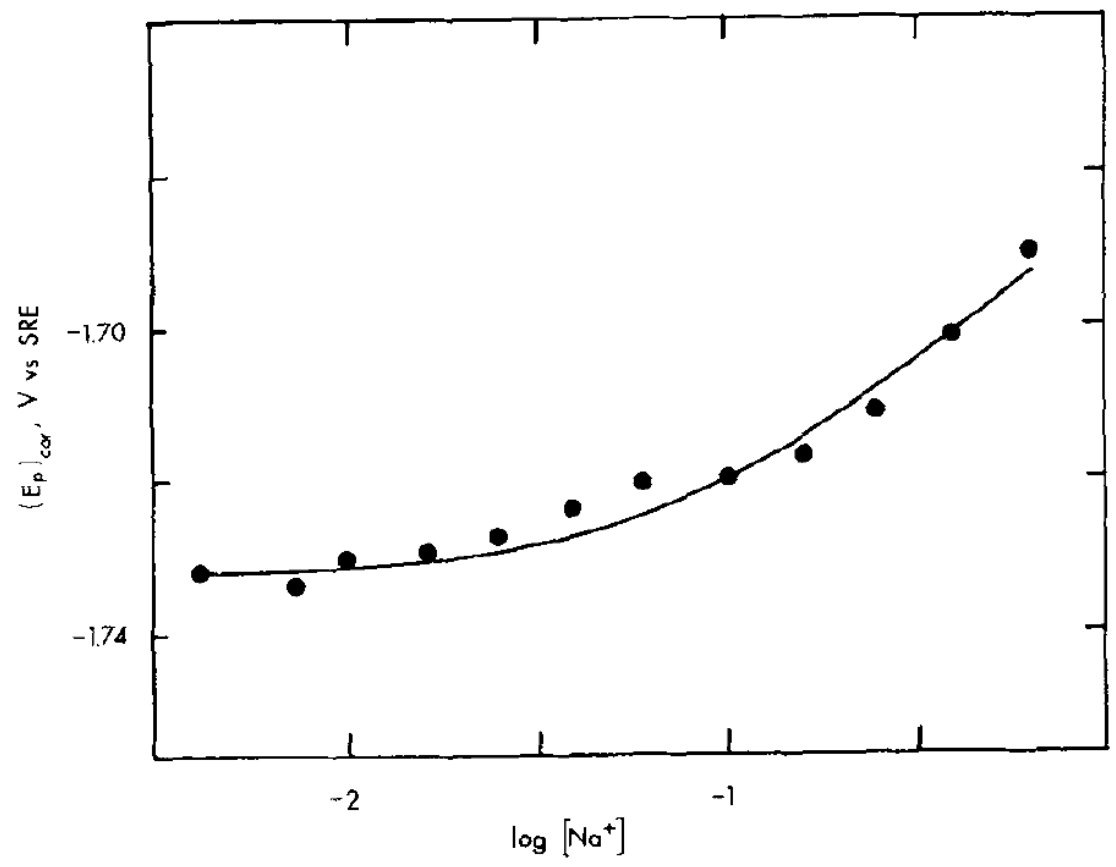

Fig. 1. Corrected peak potentials for reduction of diethyl fumarate in DMSO as a function of sodium concentration. Concentration of diethyl fumarate, $0.96 \mathrm{mM}$; scan rate, $0.050 \mathrm{~V} / \mathrm{sec}$. Peak potentials corrected for effect of chemical reactions following the initial electron transfer (see text).

Peak potentials corrected in this manner are presented in Fig. 1. The residual dependence of peak potential on sodium concentration should be due only to the first factor (ion pair formation) and the data should be interpretable in terms of the equation (15).

\section{$\left(E_{\mathrm{p}}\right)_{\text {cor. }}=E_{1 / 2}-0.0285+0.0592 \log \left(1+K C_{\mathrm{Na}}\right) \quad[7]$}

where $E_{1 / 2}$ is the half-wave potential for reaction [1]. The curve in Fig. 1 is that predicted by Eq. [7] with $\mathrm{E}_{1 / 2}=-1.704 \mathrm{~V} v s$. SRE and $K=5.8$ $M^{-1}$.

The final two rate constants, $\mathrm{k}_{2}$ and $\mathrm{k}_{3}$, can be obtained by finding the values which best fit Eq. [6] using the experimental values of $k_{\text {obs }}$ and the $k_{1}$ and $\mathrm{K}$ which were evaluated above. Figure 2 shows the curve predicted by Eq. [6] for $\mathrm{K}=5.8 \mathrm{M}^{-1}, \mathrm{k}_{1}=1.4 \times 10^{3}, \mathrm{k}_{2}=5.0$ $\times 10^{4}$, and $\mathrm{k}_{3}=3.1 \times 10^{5}$ liter $\cdot \mathrm{mole}^{-1} \mathrm{sec}^{-1}$. The ionic strength was substantially greater for the four highest sodium concentrations than it was for those of $0.1 \mathrm{M}$ and below. This could have affected the rate constants though the important reactions in this region of 
concentration (reactions [4] and [5]) are not ion-ion reactions and should not be highly dependent on ionic strength. An alternative fit for sodium concentrations of $0.10 \mathrm{M}$ and below gives $\mathrm{k}_{2}=6.8 \times 10^{4}$ and $\mathrm{k}_{3}$ $=2.0 \times 10^{5}$ liter $\cdot \mathrm{mole}^{-1} \mathrm{sec}^{-1}$. The model assumes that the rate of ion pairing is much greater than the dimerization reactions. Ion pairing rate constants are known to be large. For example, the over-all rate constant for sodium exchange in the 2, 5-di-tert.-butyl-1, 4benzoquinone radical anion-sodium ion pair is about $10^{8}$ liter $\cdot \mathrm{mole}^{-1} \mathrm{sec}^{-1}(16)$. In summary, for DMSO as solvent, ion pairing is weak but the rate of dimerization of the ion pairs is

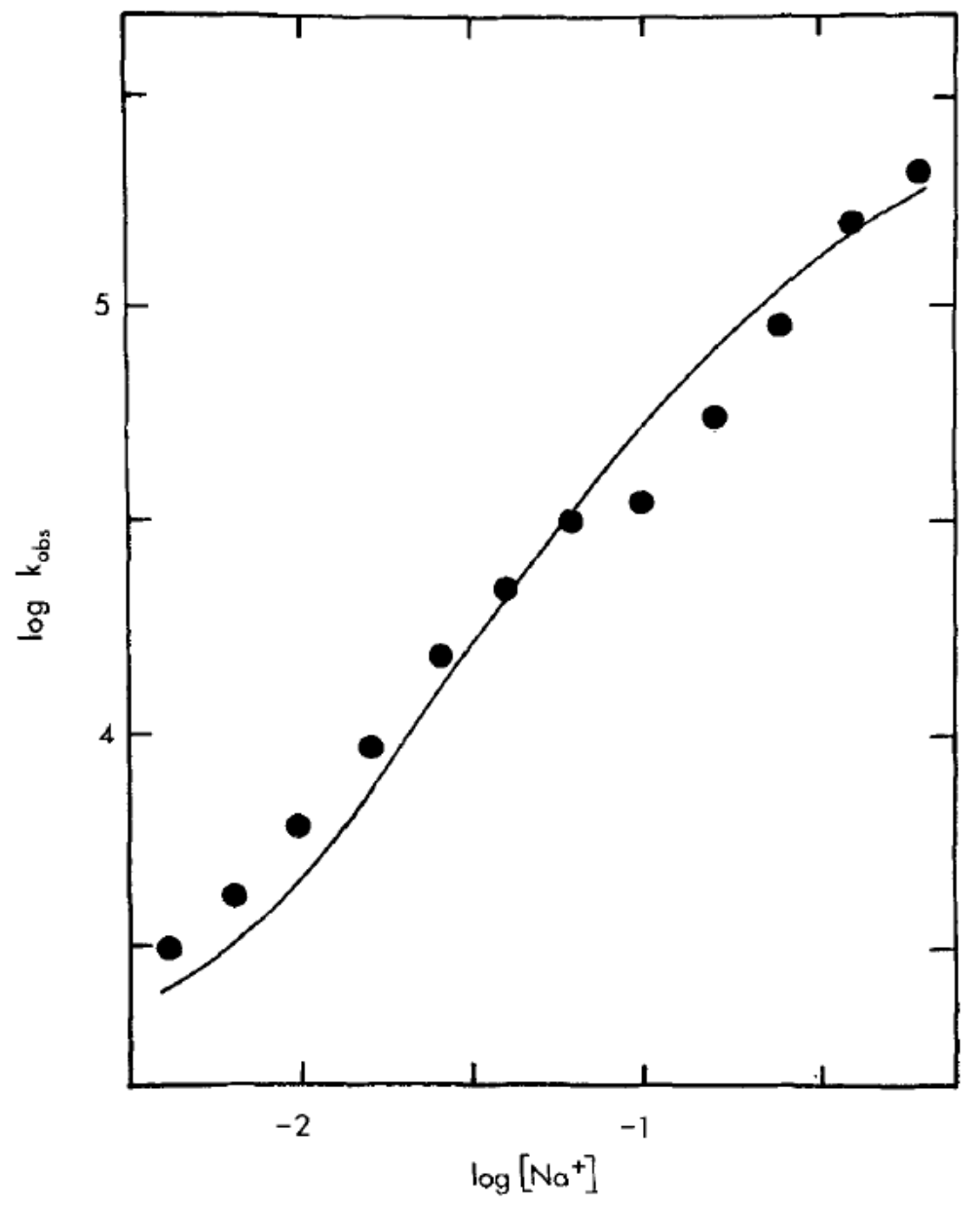

Fig. 2. Observed rate constants for dimerization of radical anions of diethyl fumarate in DMSO as a function of sodium concentration. Concentration of diethyl fumarate, $0.96 \mathrm{mM}$. Curve is Eq. [6] with $K=5.8 \mathrm{M}^{-1}, \mathrm{k}_{1}=1.4 \times 10^{3}, \mathrm{k}_{2}=5.0 \times 10^{4}$, and $\mathrm{k}_{3}=3.1 \times 10^{5}$ liter $\cdot \mathrm{mole}^{-1} \mathrm{sec}^{-1}$. 
about two orders of magnitude greater than that of the free radical anions. At low sodium concentrations, the dimerization proceeds by reactions [3] and [4], and as the sodium concentration is increased, reaction [5] becomes important while reaction [3] wanes.

When AN was used as solvent, the dimerization reactions were extremely rapid in the presence of sodium ions. With as little as $2 \mathrm{mM}$ sodium, no oxidation peak was obtained for a cyclic voltammogram of $0.29 \mathrm{mM} 1$ at $50 \mathrm{~V} / \mathrm{sec}$. This means that $\mathrm{k}_{\mathrm{obs}}$ is greater than about $10^{6}$ liter -mole-lsec ${ }^{-1}$. This greatly enhanced rate is due to the greater tendency for ion pair formation in AN as compared to DMSO. Even at low sodium concentrations, the ion pair is the predominant form of the anion radical, i.e., $K C_{N a}>>1$. Under this condition (and $\mathrm{k}_{3}>\mathrm{k}_{2}>\mathrm{k}_{1}$ as was observed in DMSO) Eq. [6] reduces to $\mathrm{k}_{\mathrm{obs}}=\mathrm{k}_{3}$ and the observed rate constant is no longer a function of sodium concentration. As a result, the kinetic effect on the peak potential for the reduction of 1 in AN will be a constant and any shift in peak potential as the sodium concentration is varied must be attributed to the ion pairing (reaction [2]). The effect is described by Eq. [7] which predicts that the peak potential should shift $59 \mathrm{mV}$ for a tenfold change in sodium concentration when the ion pair is the predominant species $\left(K_{\mathrm{Na}}>>1\right)$.

Peak potentials for the reduction of 1 in AN are presented in Fig. 3 along with a line of the theoretical $59 \mathrm{mV}$ slope. These data are consistent with a reaction scheme in which most of the radical anions exist as ion pairs, and the dimerization proceeds by reaction between these ion pairs (reaction [5]). 


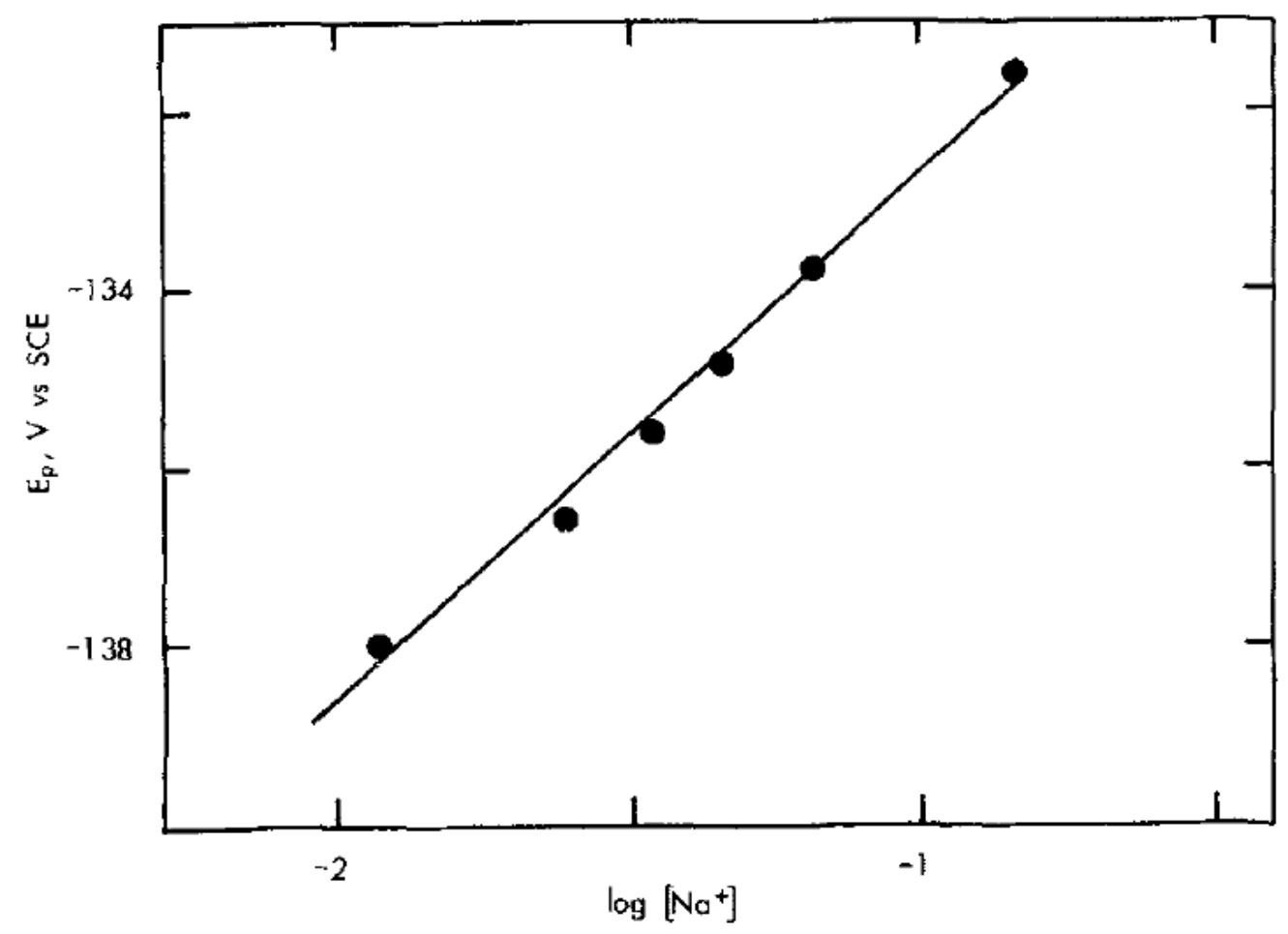

Fig. 3. Peak potentials for reduction of diethyl fumarate in $A N$ as a function of sodium concentration. Concentration of diethyl fumarate, $0.29 \mathrm{mM}$; scan rate, 0.100 $\mathrm{V} / \mathrm{sec}$.

In conclusion, it has been possible to correlate the data for the reduction of 1 in DMSO containing sodium to the mechanism given by reactions [1] - [5]. The ion pair formation constant and the three rate constants were evaluated. In AN, the same mechanism is probably active but the formation constant of the ion pair is large enough that only the pathway involving dimerization of ion pairs is observed.

\section{Acknowledgment}

This research was supported by the National Science Foundation, Grant Number GP-19579. Acknowledgment is also made to the donors of the Petroleum Research Fund, administered by the American Chemical Society, for partial support of this work. Most of the computer equipment was obtained through National Science Foundation Grant Number GP-12221.

Manuscript submitted Jan. 2, 1974; revised manuscript received Feb. 28, 1974. 
NOT THE PUBLISHED VERSION; this is the author's final, peer-reviewed manuscript. The published version may be accessed by following the link in the citation at the bottom of the page.

Any discussion of this paper will appear in a Discussion Section to be published in the June 1975 JOURNAL. All discussions for the June 1975 Discussion Section should be submitted by Feb. 1, 1975.

\section{REFERENCES}

1. W. V. Childs, J. T. Maloy, C. P. Keszthelyi, and A. J. Bard, This Journal, 118,874 (1971).

2. V. J. Puglisi and A. J. Bard, ibid., 119, 829 (1972).

3. E. Lamy, L. Nadjo, and J. M. Saveant, J. Electroanal. Chem., 42, 189 (1973).

4. S. C. Rifkin and D. H. Evans, This Journal, In press.

5. J. P. Zimmer, J. A. Richards, J. C, Turner, and D. H. Evans, Anal. Chem., 43, 1000 (1971).

6. A. Lasia, J. Electroanal. Chem., 42, 253 (1973).

7. T. Fujinaga, K. Izutsu, and T. Nomura, ibid., 29, 203 (1971).

8. T. M. Krygowski, ibid., 35, 436 (1972).

9. V. Gutmann, Chem. Brit., 7, 102 (1971).

10. R. L. Kay, B. J. Hales, and G. P. Cunningham, J. Phys. Chem., 71, 3925 (1967).

11. R. C. Buchta and D. H. Evans, Anal. Chem., 40, 2181 (1968).

12. P. E. Whitson, H. W. VandenBorn, and D. H. Evans, ibid., 45, 1298 (1973).

13. M. L. Olmstead, R. G. Hamilton, and R. S. Nicholson, ibid., 41, 260 (1969).

14. S. W. Feldberg, in "Electroanalytical Chemistry," Vol. 3, A. J. Bard, Editor, pp. 199-296, Marcel Dekker, Inc., New York (1969).

15. R. S. Nicholson and I. Shain, Anal. Chem., 36, 706 (1964).

16. A. W. Rutter and E. Warhurst, Trans. Faraday Soc., 66, 1866 (1970).

Journal of the Electrochemical Society, Vol. 121, No. 7 (July 1974): pg. 882-883. DOI. This article is (C) Electrochemical Society and permission has been granted for this version to appear in e-Publications@Marquette. Electrochemical Society does not grant permission for this article to be further copied/distributed or hosted elsewhere without the express permission from Electrochemical Society. 